\title{
Antioksidan Baharatların Osmanlı Saray Mutfağındaki Yeri
}

\author{
Sibel Ayyıld1z* \\ Karabük Üniversitesi \\ Eflani Meslek Yüksekokulu \\ orcid.org/0000-0003-0701-2445
}

\author{
Fulya Sarper \\ Hacı Bayram Veli Üniversitesi \\ Turizm Fakültesi \\ orcid.org/0000-0001-6386-9385
}

\begin{abstract}
$\ddot{O} z$
Baharat, tarih boyunca toplumların kültürel yaşamları, ekonomileri, politikaları, dini davranışları ve gelişmeleri üzerine etkili olmuştur. Gıdalara lezzet vermek amacıyla kullanılan baharatlar antimikrobiyal ve antioksidant etkileriyle de gıdaları koruyucu özelliğe sahiptir. Araştırmanın temel amacl, antioksidan baharatların Osmanlı mutfak kültüründe kullanımlarmın envanterini çıkarmak ve Osmanlı yemek türlerinin antioksidan baharatlarla ilişkisini incelemektir. Çalışma Osmanlı mutfaklarında yer alan çorbalar, kebaplar, yahni ve pilakiler, sebze yemekleri ve dolmalar, pilavlar, tatllar, şerbetler ve hoşaflarda kullanılan antioksidan baharatlarla sınırlandırılmıştır. Araştırmada antioksidan özellik gösteren, Karabiber, Kişniş, Kimyon, Safran, Tarçın, Zerdeçal, Zencefil ve Karanfil gibi baharatların Osmanlı mutfak kültüründe kullanımları incelenmiştir. Osmanlı mutfă̆ında baharat kullanımı genel olarak incelendiğinde en çok karabiber ve tarçın baharatlarının kullanıldığı görülmektedir. Karabiber tuzlu yemeklerde kullanılırken, tarçın hem tuzlu hem de tatl yemeklerde kullanılmıştır. Zerdeçal baharının, kebap, pilav ve

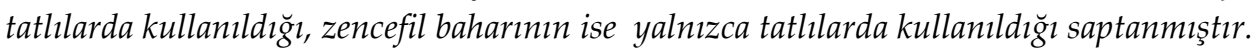

Anahtar Kelimeler: Osmanlı Mutfă̆ında Baharatlar, Antioksidan Baharatlar ve Kullanımları

\section{The Importance of Antioxidant Spices in Ottoman Cuisine}

\section{Abstract}

Throughout history, spice has influenced the cultural life, economies, politics, religious behaviors and the development of societies. The spices used for flavoring the foods have antimicrobial and antioxidant effects. The main aim of the study is to determine the use of antioxidant spices in the Ottoman cuisine and to examine the relationships between the antioxidant spices and Ottoman cuisine. The study is limited to the antioxidant spices which is used in soups, kebabs, meat stews, vegetable dishes and tuffed peppers, pilafs, desserts, sherbets, and fruit stews. In this study, the use of antioxidant spices in the Ottoman cuisine such as Black Pepper, Cilantro, Cumin, Saffron, Cinnamon, Turmeric, Ginger and Clove, was examined. When the use of species in Ottoman cuisine was examined it was seen that pepper and cinnamon spices are commonly used. Black pepper was used in salty dishes, while cinnamon was used in both salty and sweet dishes. Turmeric was used in kebabs, rice dishes and desserts, while ginger was used only in desserts. While Turmeric spring are used in kebab, pilav and desserts, it is determined that ginger spring is only used in desserts.

Keywords: Spices in the Ottoman Cuisine, Antioxidant Spices and their Uses

\section{Giriş}

'Bahar' kelimesi Arapçada 'koku' demektir. Çoğul bir kelime olan baharat kokular anlamına gelir ve Türkçe'de baharata '1ssı ot' denilmiştir (Yerasimos, 2014: 51). Baharat, tarih boyunca toplumların kültürel yaşamları, ekonomileri, politikaları, dini davranışları ve gelişmeleri üzerine etkili olmuştur. Colombus, Vasco da Gama ve Portekizli denizci Ferdinand Magellan gibi kaşifleri doğudaki zengin baharat 
kaynaklarını aramak üzere maceraya atmış, hatta baharat kaynaklarını arama macerası birçok savaşın nedeni olmuştur (Mete, 2017: 15). Her ne kadar eski uygarlıklarda, tüm aromatik bitki ürünleri otlar olarak bilinmiş olsa da günümüzde otlar ve baharatlar arasında keskin bir ayrım vardır. Kişniş, nane ve fesleğen gibi küçük aromatik ılıman yapraklı bitkiler (Latince 'herba' anlamına gelen 'ot' veya 'yeşil saplar' sözcüğünden türetilmiştir) otlar olarak belirlenirken, çiçeklerden elde edilen kuru kırıntı malzemeler, meyveler, tomurcuklar, tohumlar, kabuk ve karabiber, karanfil, tarçın gibi belirli tropik kök sap bitkiler baharat olarak bilinir (Narsimhan, 2009: 121). Baharatlar, insanoğlunun yemeklerinin aroma ve lezzetini düzeltmek, artırmak amacıyla binlerce yıldır yararlandıkları doğal gıda katkılarıdır (Yeşilada, 2012: 39). Fakat yalnızca lezzetlendirici olarak değil aynı zamanda tedavi amaçlı da kullanılmıştır. Örneğin zencefil, biber, kişniş, kimyon, tarçın gibi baharatlar sıcak tabiatlı besinler olarak adlandırılmaktadır ve bu özelliklerinden dolayı ilaç olma vasıfları ön plana çıkmaktadır (Gürsoy, 2012: 32). Demirçivi ve Altaş'a göre (2016) ise baharatlar; “bütün, parçalanmış ya da ögütülmüş biçimde olabilen; yemeklerdeki birincil işlevi besleyicilikten ziyade lezzetlendirici özelliği olan; yiyecek ve içeceklerdeki lezzete yada keskinliğe katkı veren; herhangi bir uçucu yağ bulundurmayan; tatlandırıcı kullanılmamış; katkı maddesi eklenmemiş; kurutulmuş güzel, kuvvetli veya keskin kokulu sebze veya bitki özleridir".

Tarihi boyunca 'Yükte hafif, pahada ağır' olma özelliğiyle, uzun mesafeli ticaretin en önemli kalemi haline gelen baharat, Suriye ve Misır'dan Anadolu ve Avrupa'ya dağılmıştır. Uzakdoğu ve Hint kökenli olan baharat Yemen vasıtasıyla Suriye ve Mısır'a ulaşıp buralardan diğer Osmanlı topraklarına ve Avrupa'ya ihraç edilmiştir (Bilgin, 2004: 220). Coğrafi konumu, iklim ve bitki çeşitliliği, tarımsal potansiyeli, geniş yüzölçümü sayesinde Türkiye tıbbi ve aromatik bitkiler ticaretinde önde gelen ülkelerden biri olmuştur. Türkiye Florası'na göre, 174 familyaya ait 1251 cins ve 12.000 'den fazla tür ve tür altı taksonu (alt tür ve varyete) ile oldukça zengin bir floraya sahiptir. Bu taksonların 234'ü yabancı kaynaklı ve kültür bitkisi iken, geriye kalan diğer türler ise yurdumuzda doğal yayılış gösteren bitkilerdir (Faydaoğlu ve Sürücüoğlu, 2011: 53). Dünya genelinde yaklaşık 100 ülkeye tıbbi aromatik bitki ihracatı yapan Türkiye kekik, defne, kimyon, kebere, çay ve haşhaş tohumu ve alkaloitlerin önemli tedarikçi ülkesi konumundadır. Ayrıca dış satımın önemli bir kısmını Kuzey Amerika, Avrupa Birliği, Latin Amerika, Uzak Doğu ve Kuzey Afrika ülkelerine yapmaktadır (Keykubat, 2016: 15).

Bu çalışma Osmanlı mutfağında kullanılan antioksidan baharatlar ve o dönem yemeklerindeki kullanımı hakkında yapılmış olan çalışmalar derlenerek, listeler ve tablolar şeklinde sunulmuştur.

\section{Araştırmanın Amacı, Önemi ve Yöntemi}

Araştırmanın temel amacı, antioksidan baharatların Osmanlı mutfağında kullanım durumlarını değerlendirmek ve bu kapsamda varlığı boyunca Osmanlı yemek çeşitlerinin antioksidan baharatlarla ilişkisini incelemektir. Osmanlı Mutfağında kullanılan bu önemli baharatlar, kullanılan yemeğin türüne göre incelenecektir. Hangi 
baharatların hangi yemeklerde kullanıldığı ile ilgili detaylı bir inceleme olacağından dolayı çalışmanın mutfak kültürü ile ilgilenen araştırmacılara katkı sağlayacağı düşünülmektedir. Çalışma ayrıca konuyla ilgili olan okuyuculara baharatlarla lezzet uyumu hakkında bilgi sağlayacaktır.

Çalışma Mart 2018-Temmuz 2018 tarihleri arasında iki araştırmacı tarafından yapılmıştır. Bu araştırma nitel araştırma yönteminde doküman incelemesi yoluyla yapılmıştır. Yıldırım ve Şimşek (2016: 189)'e göre doküman incelemesi, araştırılması hedeflenen olgu veya olgular hakkında bilgi içeren yazılı materyallerin analizini kapsar. Nitel araştırmada doküman incelemesi tek başına bir veri toplama yöntemi olabileceği gibi diğer veri toplama yöntemleri ile birlikte kullanılabilir. Çalışma ikincil veri türlerinden olan yazılı belgelerin incelenmesiyle elde edilmiştir. İkincil veriler olarak Osmanlı Saray Mutfak Kayıtlarından ve Seyahatnamelerden elde edilen yazılı kaynaklar ile 7 adet Osmanlı mutfağı yemek kitapları kullanılmıştır. Kullanılan bu kaynaklar, veriler ile oluşturulan tablolarda ve çalışmanın kaynakça kısmında yer almaktadır. İkincil veriler hem nitel hem de nicel araştırmalarda; hem betimleyici hem de açıklayıcı çalışmalarda kullanılabilir. İkincil veri türleri; belgeler (yazılı olan: kitaplar, dergiler, raporlar, vb; yazılı olmayanlar: televizyon radyo, teyp kayıtları vb.), çok kaynaklı çalışmalar ve anket olarak sınıflandırılır (Coşkun vd., 2017: 81).

İki kısımdan oluşan çalışmada öncelikle Osmanlı mutfağında yer alan yemeklerde kullanılan antioksidan baharatların neler oldukları ilgili yazında birikmiş bilgiden yararlanma suretiyle araştırmalar yapılmıştır. Bu araştırma çerçevesinde literatürde bulunan yazılı kaynaklar ve web temelindeki açık erişimli kaynaklarda yer alan Osmanlı Mutfak kültürü ile ilişkili çalışmalar ve Osmanlı yemek kitapları araştırmanın kaynağını oluşturmuştur. Çalışmada antioksidan baharatların özellikleri ve kullanım alanlarına değinildikten sonra antioksidan baharatlar antropolojik açıdan ele alınmıştır. Çalışmanın ikinci kısmında ise, alan yazınında yer alan 7 adet Osmanlı mutfağı yemek kitaplarındaki tarif ve reçeteler detaylı bir şekilde taranarak yemeklerde yer alan antioksidan baharatların kullanımı incelenmiştir. Osmanlı mutfağ1 yemek kültüründeki yemekler, incelenen kitaplarda yer alan yemek başlıklarına göre kategorize edilmiştir. Çorbalar (8 adet), Kebaplar (8 adet), Yahni ve Pilakiler (8 adet), Sebze yemekleri ve Dolmalar (8 adet), Pilavlar (8 adet), Hamur işleri ve Börekler ( 8 adet), Tatlılar, Şerbetler ve Hoşaflar (8 adet) şeklinde kategorilere ayrılmıştır. 8'er yemek çeşidinin incelendiği bu araştırma, Osmanlı mutfağında kullanılan ve antioksidan özellik gösteren, Karabiber, Kişniş, Kimyon, Safran, Tarçın, Zerdeçal, Zencefil ve Karanfil baharatları ile sınırlandırılmıştır. Çalışmada elde edilen veriler ile aşağıda yer alan Bulgular kısmı oluşturulmuştur.

\section{Antioksidan Bitki ve Baharatlar}

Gıdalarda daha çok lezzet amaçlı kullanılan baharatlar son yıllarda özellikle antimikrobiyal ve antioksidan etkileriyle de gidaları koruyarak raf ömrünü arttırmaktadır. Günümüzde minimal işlem görmüş, herhangi bir katkı maddesi içermeyen gıdaların tüketimine yönelik potansiyel talebin artması, baharat ve özütlerinin gıda maddelerinde koruma amaçlı kullanımlarını da arttırmıştır (Göncü ve 
Akın, 2017: 44). Oksidatif bozulmayı önleyen veya geciktiren bileşikler için kullanılan antioksidan terimi, daha geniş bir ifadeyle gidalarda oksijenle reaksiyona girerek, gıdalar içindeki olumsuz etkileri engelleyen maddeler olarak tanımlanabilmektedir (Çolak ve Ulusoy, 2005: 43, Erbaş vd., 2008: 1052). Fenolik ve flavonoidlerce zengin baharatların güçlü antioksidan(oksitlenmeyi engelleyici) etkileri vardır. Baharatların günlük belirli oranlarda tüketilmesi vücudun gereksinim duyduğu antioksidan aktivitesini desteklemektedir (Yiğit, 2016: 219). Antioksidanlar, çoğunlukla serbest radikal süpürme özelliği nedeniyle hücresel hasarı geciktirir veya inhibe eder (Lobo vd., 2010: 117). Erken yaşlanmayı önlemek, kanser ve diğer hastalıklara karşı koruma sağlamak ve vücudun direncini arttırmak için bu desteklerin önemi oldukça büyüktür (Yiğit, 2016: 219). Koca ve Karadeniz' in yapmış olduğu bir çalışmaya göre (2005: 234), Diyette yer alan antioksidanlar zihinsel performansı geliştirirken, sinirsel dejeneratif rahatsızlıkların oluşumunu engellemektedir. Parkinson ve Alzheimer gibi yaşa bağlı dejeneratif hastalıklardan korunmaya yardımcı olmaktadır. Ayrıca kalp hastalığı ve kanseri önlediği de düşünülmektedir.

Antioksidan özellik gösteren birçok bitki ve baharat labiatae(Lamiaceae) familyasına aittir. Labiatae familyasına ait cinsler özellikle terpenik bileşikleri, flavonoid, fenolik asitleri içermesi nedeniyle önemli fizyolojik aktivitelere (antioksidan ve antimikrobiyel) sahip bitkileri içermektedir (Öğ̈̈t, 2014: 27, Çoban \& Patır, 2010: 8). Labiatae familyası, özellikle Akdeniz ülkelerinde doğal olarak yetişen ve 1lıman iklim kuşağında yer alan, birçok ülkede de kültürü yapılan bitkilerin oluşturduğu, 200 kadar cins ve 3000'in üzerinde türü içeren zengin bir familyadır. Labiatae familyasına ait bitkilerin çoğu antik çağlardan bu yana halk ilacı olarak çeşitli hastalıkların tedavisinde kullanılmalarının yanı sıra tıpta, gıda endüstrisinde, parfümeri ve kozmetikte yer alan bitkilerdir (Göncü ve Akın, 2017: 46). Bitki ve baharatların kimyasal bileşenleri farklı olduğu için göstermiş oldukları antioksidan etkiler de birbirinden farklıdır. Türkiye'de yetiştirilen 31 çeşit aromatik bitkinin antioksidan etkisinin ayçiçeği yağında incelendiği bir çalışmada en güçlü antioksidan etkiye sahip bitkisinin biberiye olduğu, bunu sırasıyla adaçayı, sumak ve kekik gibi bitkilerin izlediği görülmüştür (Çoban ve Patır, 2010: 10). Çalışmaya dahil edilen Karabiber, Kişniş, Kimyon, Safran, Tarçın, Zerdeçal, Zencefil ve Karanfil baharatları olmuştur. Bu baharatların Osmanlı mutfağında oldukça önemli olduğu belirlenmiştir. Ayrıca çalışma kapsamına alınan bu baharatların antioksidan özellik gösterdiği ifade edilmiştir (Paur vd. 2011, Lobo vd. 2010). Çalışmada değerlendirilen baharatlarla ilgili bilgiler Tablo 1'de ayrıntılı bir şekilde incelenmiştir. 
Tablo 1. Antioksidan Baharatların Özellikleri ve Kullanım Alanları

\begin{tabular}{|c|c|c|c|}
\hline Baharatlar & Özellikleri & Kullanım Alanları & Kaynakça \\
\hline $\begin{array}{c}\text { Tarçın (Cinnamomun } \\
\text { zeylanicum) }\end{array}$ & $\begin{array}{l}\text { Tarçın gerçek ya da } \\
\text { Seylan tarçını olarak } \\
\text { adlandırılır. Odunsu } \\
\text { kokusu ve tatlımsı lezzeti } \\
\text { vardır. Çin tarçını ise } \\
\text { yalancı tarçın (nagkesar) } \\
\text { olarak adlandırılır, daha } \\
\text { acı ve yoğundur. }\end{array}$ & $\begin{array}{l}\text { Tarçın kabuğu yağı değerli } \\
\text { lezzet vericilerden biridir. } \\
\text { Ayrıca iştah açıcı, keskin ve } \\
\text { orta sıcaklıkta bir baharattır. } \\
\text { Tatlı, şekerleme, pasta, } \\
\text { bisküvi, sütlü tatlılarda, boza } \\
\text { sahlep gibi içeceklerde, sos ve } \\
\text { çeşitli içeceklerin yapımında } \\
\text { yaygın kullanılmaktadır. }\end{array}$ & 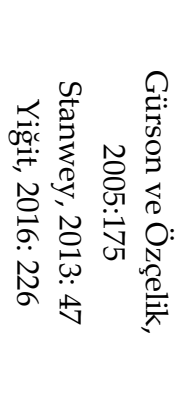 \\
\hline $\begin{array}{r}\text { Karanf } \\
\text { caryo }\end{array}$ & $\begin{array}{c}\text { Yaprak dökmeyen } \\
\text { ağaçlardan elde edilir. } \\
\text { Çiçeklerin kurutulmuş } \\
\text { tomurcukları “karanfil” } \\
\text { adını alır. Karanfile koku } \\
\text { ve lezzetini veren } \\
\text { "eugenol" adındaki } \\
\text { uçucu yağdır. }\end{array}$ & $\begin{array}{l}\text { İştah açıcı tatlı yiyecekler ile } \\
\text { sıcak şarap gibi içeceklerde } \\
\text { lezzetlendirici olarak } \\
\text { kullanılır. Ayrıca Et ve balık } \\
\text { haşlamalarında, av etlerinde, } \\
\text { salamuraya yatırılan meyve ve } \\
\text { sebzelerde, çeşitli } \\
\text { Kompostolarda, tatlılarda, } \\
\text { reçellerde kek ve } \\
\text { kurabiyelerde lezzetlendirici } \\
\text { olarak da kullanılmaktadır. }\end{array}$ & 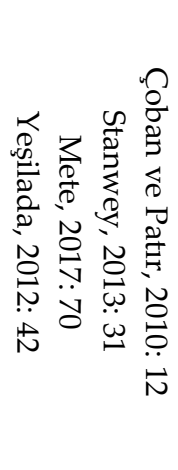 \\
\hline 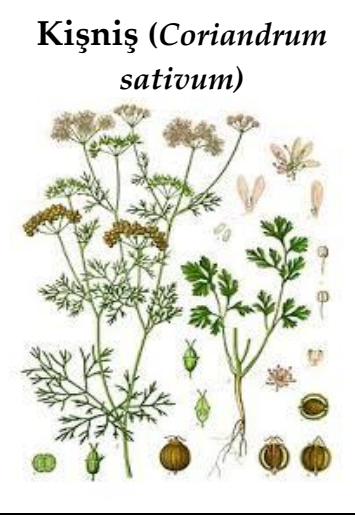 & $\begin{array}{l}\text { Tatlı ve yakıcı tadı } \\
\text { vardır, ayrıca kendisine } \\
\text { has kokuya sahip } \\
\text { olabilmesi için bitki } \\
\text { tohumunun } \\
\text { olgunlaşması } \\
\text { gerekmektedir. En } \\
\text { önemli özelliklerinden } \\
\text { biri antimikrobik } \\
\text { olmasıdır. }\end{array}$ & $\begin{array}{c}\text { Yeşil yaprakları sos, salata, } \\
\text { çorba ve sebze yemeklerinde, } \\
\text { zeytinyağlılarda, mezelerde, } \\
\text { bazı soğuk soslarda } \\
\text { kullanılırken, kurutulmuş } \\
\text { meyveleri gıdalara aroma } \\
\text { kazandırmak amacıyla } \\
\text { kullanılmaktadır. Ayrıca } \\
\text { kişniş tohumları turşulara, } \\
\text { salamuralara, balık } \\
\text { konservelerine aroma katmak } \\
\text { için kullanılmaktadır. }\end{array}$ & 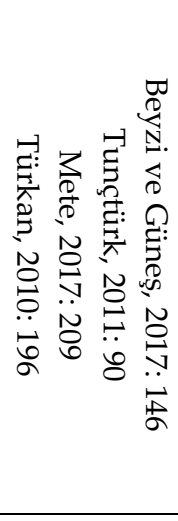 \\
\hline Safran (Crocus sativus) & $\begin{array}{l}\text { Mor çiçekli, sonbaharda } \\
\text { açan çiğdem bitkisine } \\
\text { safran denilmektedir. } \\
\text { Önemli bir gelir kaynağı } \\
\text { olan bitki, Avrupa } \\
\text { devletlerinde ve Osmanlı } \\
\text { devletinde önemli bir } \\
\text { yere sahip olmuştur. }\end{array}$ & $\begin{array}{c}\text { Soslara, Şekerlemelere, } \\
\text { keklere, pastalara, } \\
\text { kurabiyelere ve birçok yöresel } \\
\text { tatlılara aroma ve rengi } \\
\text { zenginleştirmek için kullanılır. } \\
\text { Ayrıca, soslu balık } \\
\text { yemeklerinde, pilavlara, } \\
\text { çorbalara, likörlere ve olmazsa } \\
\text { olmaz zerde tatlısına baharat } \\
\text { olarak katılmaktadır. }\end{array}$ & 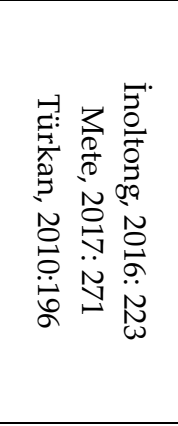 \\
\hline
\end{tabular}




\begin{tabular}{|c|c|c|c|}
\hline Karabiber (Piper & $\begin{array}{l}\text { Çok yaygın olarak } \\
\text { kullanılan karabiber } \\
\text { olgunlaşmış biber } \\
\text { meyvelerinden elde } \\
\text { edilir. Antioksidan, } \\
\text { antimikrobiyel ve ateş } \\
\text { düşürücü özelliğe } \\
\text { sahiptir. }\end{array}$ & $\begin{array}{l}\text { Karabiber klasik tatlılar hariç } \\
\text { hemen hemen tüm } \\
\text { yemeklerde kullanılabilir. Acı } \\
\text { tat vermek için kullanılan } \\
\text { karabiber, Et suları, ızgara ve } \\
\text { kızartmalarda, her türlü çorba, } \\
\text { bakliyat ve midye } \\
\text { yemeklerinde, kümes hayvanı } \\
\text { etlerinde, salatalarda ve sebze } \\
\text { yemeklerinde } \\
\text { kullanılmaktadır. }\end{array}$ & 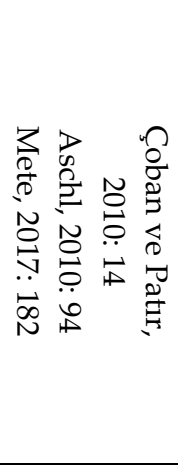 \\
\hline$\prod_{0 \rightarrow-\infty}$ & $\begin{array}{c}\text { Maydanoz/havuç } \\
\text { familyasından yeşilimsi } \\
\text { kahverengi meyveleri } \\
\text { olan biberli, tatlımsı, } \\
\text { miskli, hafif acı bir } \\
\text { baharattır. }\end{array}$ & $\begin{array}{l}\text { Kimyon daha çok pastırma ve } \\
\text { sucuk yapımında } \\
\text { kullanılırken, peynirlerin } \\
\text { yapımında, kek, ekmek, } \\
\text { kurabiye, bazı likör türleri ve } \\
\text { etli yemeklere çeşni vermesi } \\
\text { için kullanılmaktadır. Izgara et } \\
\text { ve ciğer kebaplarında da } \\
\text { kullanılır. }\end{array}$ & 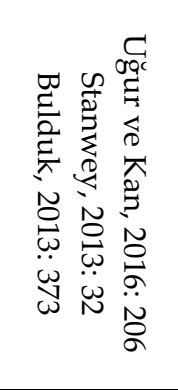 \\
\hline & $\begin{array}{l}\text { Zencefil ailesine aittir ve } \\
\text { uzun ömürlüdür. } \\
\text { Zerdeçal büyüme } \\
\text { sürecinden sonra kökü } \\
\text { topraktan çıkarılır. Daha } \\
\text { sonra pişirilerek } \\
\text { kurutulan zerdeçal toz } \\
\text { haline getirilerek } \\
\text { kullanılır. }\end{array}$ & $\begin{array}{l}\text { Et yemeklerinde, Balık çorbası, } \\
\text { pilav, soslar, tavuk bulyon, } \\
\text { peynir turşusu, söğüş ve çeşitli } \\
\text { sebze yemeklerine çeşni olarak } \\
\text { katılır. Tahıl yemeklerinde, } \\
\text { hardal ve turşu yapımında, } \\
\text { tatlı kek yapımında kullanılır. } \\
\text { Kimi zaman safranın yerine de } \\
\text { kullanılmaktadır. }\end{array}$ & 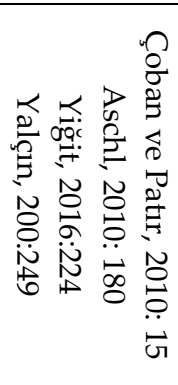 \\
\hline 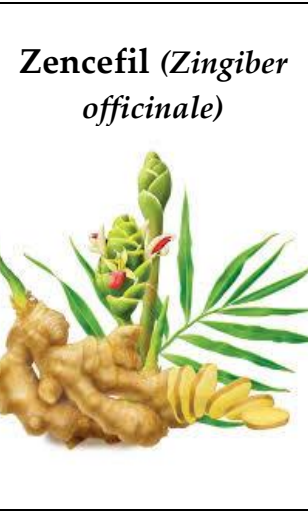 & $\begin{array}{c}\text { Anavatanı Endonezya } \\
\text { olan Zencefil, genellikle } \\
\text { kökleriyle çoğalan } \\
\text { aromalı, keskin ve acı bir } \\
\text { baharattır. Taze, kuru ve } \\
\text { öğütülmüş kuru } \\
\text { kökünden yararlanılır. }\end{array}$ & $\begin{array}{c}\text { Zencefilden genellikle şerbet, } \\
\text { meşrubat, likör, şarap, turşu, } \\
\text { reçel yapımında yararlanılır. } \\
\text { Ayrıca çorbalarda, sosis ve } \\
\text { çeşitli dolmalarda, kümes } \\
\text { hayvanları, deniz mahsuller, } \\
\text { etli yemekler, salatalar, soslar, } \\
\text { kompostolarda, çeşitli beyaz } \\
\text { peynirlerde, meyve } \\
\text { salatalarında, pastalarda, turşu } \\
\text { ve salamuralarda ve } \\
\text { çöreklerde kullanılır. }\end{array}$ & 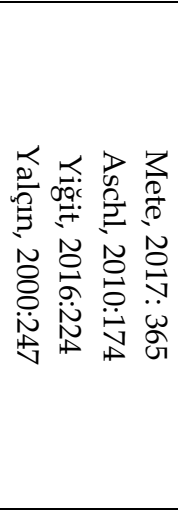 \\
\hline $\begin{array}{l}\text { riye } \\
\text { offic }\end{array}$ & $\begin{array}{c}\text { Anavatanı Akdeniz olan } \\
\text { bu bitki özellikle Avrupa } \\
\text { ve Kuzey Amerika } \\
\text { ülkelerinde yaygın olarak } \\
\text { yetiştirilir. Özellikle } \\
\text { yaprakları ve uçucu yağı } \\
\text { kullanılmaktadır. }\end{array}$ & $\begin{array}{c}\text { En çok sebze çorbalarına ve } \\
\text { soslara ve domatese yakıştığı } \\
\text { düşünülmektedir. Ayrıca kuzu } \\
\text { av hayvanları, tavuk eti, balık, } \\
\text { ızgara etlerde, sebze } \\
\text { yemeklerinde ve salatalarda } \\
\text { kullanılmaktadır. }\end{array}$ & 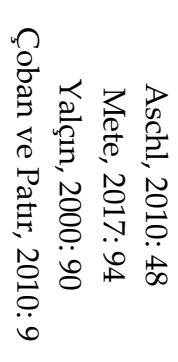 \\
\hline
\end{tabular}




\begin{tabular}{|c|c|c|c|}
\hline 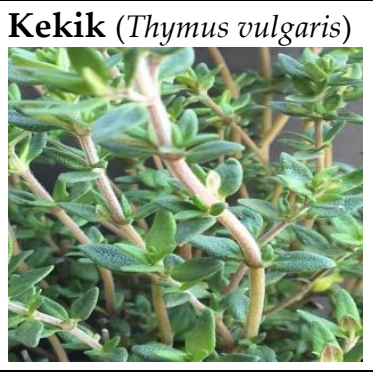 & $\begin{array}{l}\text { Kendine özgü kokusu ile } \\
\text { tanınan kekik, çimenlik, } \\
\text { tarla, orman ve } \\
\text { çayırlarda görülür. } \\
\text { Türkiye' de daha çok } \\
\text { doğada kendiliğinden } \\
\text { yetişmektedir. }\end{array}$ & $\begin{array}{l}\text { Av hayvanları, balık, tavuk } \\
\text { gibi et türlerinin yanında ve } \\
\text { marinasyonunda, çorba, } \\
\text { dolma, çeşitli soslarda, } \\
\text { domates peynir gibi ürünlerin } \\
\text { çeşnilendirilmesinde, ekmek, } \\
\text { kurabiye ve bisküvi gibi } \\
\text { hamur işlerinde de kullanılır. }\end{array}$ & 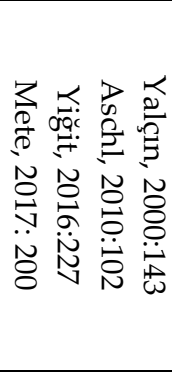 \\
\hline $\begin{array}{l}\text { Ad } \\
\text { offic }\end{array}$ & $\begin{array}{l}\text { Anavatanı Akdeniz olan, } \\
\text { Türkiye'de 90'a yakın } \\
\text { türü yetişen Adaçayı, } \\
\text { yaprakları ve çiçekleri } \\
\text { kullanılan bir baharattır. }\end{array}$ & $\begin{array}{l}\text { Balık ve deniz ürünleri, av } \\
\text { hayvanları ve kuzu } \\
\text { yemeklerinde, salam sucuk ve } \\
\text { köfte çeşnilendirmesinde, } \\
\text { 1zgaralarda, çorba ve tencere } \\
\text { yemeklerinde, soslarda, } \\
\text { salatalarda ve dolma içlerinde } \\
\text { kullanılır. }\end{array}$ & 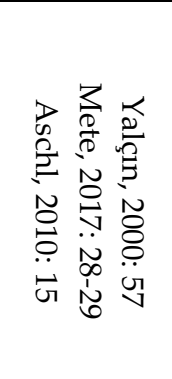 \\
\hline ria) & $\begin{array}{c}\text { Bir ağaççı olan sumak } \\
\text { bitkisi, Doğu Akdeniz } \\
\text { ülkelerinde yetiştirilen } \\
\text { hafif ekşi ve sıcak bir } \\
\text { baharattır. Meyvesi } \\
\text { ezilerek, toz halinde } \\
\text { getirilip, baharat olarak } \\
\text { kullanılır. }\end{array}$ & $\begin{array}{c}\text { Et, balık ve tavukları marine } \\
\text { etmek amacıyla kullanılırken, } \\
\text { kebab, döner, çorba, güveç, } \\
\text { pilav ve lahmacun gibi } \\
\text { yemeklerde de kullanılır. } \\
\text { Ayrıca Türkiye ve İran'da çiğ } \\
\text { soğanla birleştirilerek yemek } \\
\text { yanına aperatif amaçlı getirilir. }\end{array}$ & 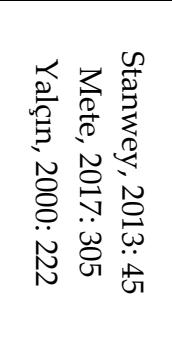 \\
\hline
\end{tabular}

\section{Baharat Kullanımının Tarihçesi ve Osmanlı Mutfak Kültüründe Baharatlar}

Sümer tableti (MÖ 3000), Çin tıbbı Pen T'Sao Ching (MÖ 2700), Hindistan'ın Ayurveda adlı metinlerinde, Charaka Samhita, Susruta Samhita ve eski yazılara dayanan Ebers Papirüsü (MÖ 1550) gibi hayatta kalan en eski tarihi kayıtlarda baharatların ilaç, kozmetik, merhem, parfüm, tütsü ve mumyalamada kullanıldığ 1 tespit edilmiştir (Narsimhan, 2009: 121). Başlangıçta baharat yalnızca insanın tat alma zevki için değil, temelde dinsel (örneğin tütsüde) ve tedavi amacıyla kullanılmıştır. Taş devri insanlarının haşhaş, melek otu ve kimyonu bildikleri belirlenmiştir (Tez, 2015: 138). M.S 5.yy'dan kalma “ İskenderiye tarifesi " isimli Roma belgesi, gümrük vergisine tabi maddeler başlığı altında toplanan, 54 kalem maldan meydana gelen bir listeden oluşmaktadır. Listede tarçın, sinameki, zencefil, beyaz biber, uzun biber, kakule gibi baharatlar yer almaktadır (Standage, 2016: 87). Baharatın gidalarda kullanımı ile ilgili ilk yazılı kayıt Mısır'da yapılan kazılarda bulunmuştur. MÖ 1500 yıllarına ait bu kayıtlarda hardalın hem yemeğe çeşni veren bir madde hem de koruyucu olarak kullanıldığı bildirilmiştir (Demirçivi \& Altaş, 2016: 90). Baharat ve diğer ticari malların en önemli aktarım yerleri, İskenderiye, Konstantinopolis ve Venedik'tir. 8.yy'dan 15. yy'a kadar Venedikliler Orta doğu ile baharat ticareti alanında tekel olmuş, bu malları diğer İtalyan kent devletlerine aktarmış ve baharat ticareti bölgeyi çok zengin yapmıştır. Başta karabiber (kara altın) olmak üzere, tarçın, muskat egemen sınıfın statü simgesi ve güç göstergesi olmuştur. Hükümdarlar birbirine 'karabiber' armağan etmiş, kimi zaman ödemeler altın yerine karabiber baharatıyla yapılmıştır (Tez, 2015: 140). 
Baharatlar ile yemek pişirmenin Romalılardan ve Müslümanlardan dünyaya miras kaldığını belirtilmiştir. Dahası Romalı askerler Yunan-Roma dünyasının en kuzey ve batıya ulaşan bölgelerine baharat taşıyarak, kıtaya baharat kullanımlarını yaygınlaştırmıştır. Ortaçă̆ ve ortaçağ sonrası Avrupa'dan farklı olarak, Osmanlı mutfağında baharatlar aşırı tüketilmemiş dahası 1lımlı kullanmıştır. Osmanlı aşçıları yiyeceklerin doğal lezzetini arttırmak için ürünlerini hafifçe baharatlamışlardır. Baharatın bu ılımlı kullanımı Osmanlı mutfağının sofistikeliğin sembolik bir ifadesi haline gelmiştir (Lewicka, 2011: 142). Yerasimos (2014)'da bu görüşü desteklemiş ve Osmanlı mutfağında her ne kadar pahalı baharatlar kullanmışsa da ölçü ve özellikle karışım konusunda aşırıya kaçılmadığı vurgulamıştır. Yemekler antik Roma, Avrupa ya da Arap mutfağının tersine, ne karışık baharatlı ne de çok salçalı olmuştur. Hatta 18. yy'dan sonra yemekler, baharat karışımları açısından da iyice sadeleşmiştir (Yerasimos, 2014: 55).

Selçuklu mutfağında safran, kimyon, susam baharatları kullanılıyorken, Fatih Sultan Mehmet'in Saray Mutfağında Tüketilen baharatları; Misk, safran, zeytin, maydanoz, hardal, sarımsak, kişniş, nane, kimyon, Eflak tuzu (eflak bölgesinden elde edilen tuz), sakız, sirke, fülfül (karabiber), tarçın, karanfil, amber olmuştur (Kızıldemir, 2014: 197). Bu çeşitliliğin artma sebebi; Ana üretim merkezlerinin ve baharat yollarının denetimlerinin fetihlerle birlikte Osmanlı Devletine geçmesiyle, Osmanlı mutfağına giren ürün çeşidi artmış bu da damak zevkinin daha da fazla gelişmesini sağlamıştır. Baharat ve bitkiler Osmanlı mutfağında genel olarak macunlar başta olmak üzere, yemeklerde ve Helvahane mamullerinde kullanılmıştır. Fırınlara da susam, anason, çörekotu, sakız ve kimyon baharatları tahsis edilmiştir (Bilgin, 2004: 221, Samancı, 2016: 74). Osmanlı mutfağının en vazgeçilmez baharatı neredeyse tüm et yemeklerinde kullanılan karabiber olmuştur. Karabiberi ise safran baharatı takip etmiştir. Pilavlarda, yahnilerde hatta tatlılarda hem lezzetlendirici hem de renklendirici olarak kullanılmıştır (Yerasimos, 2014: 54). Karabiber, tarçın, karanfil, kakule, sakız, kimyon, safran, kırmızıbiber, yenibahar, sumak, kekik, Cevz-i hindi (Hindistan cevizi) saray mutfaklarında Osmanlı mutfağında baharat olarak kullanılırken, özellikle 19.yy'da en çok tercih edilen baharat tarçın ve karabiber olmuştur (Samanc1, 2016: 176). 14. ve 15. yy'larda tatlandırıcı olarak misk, safran, kişniş, nane, kimyon, tarçın, karanfil ve amber kullanılmıştır (Gürsoy, 2013:107). 15. ve 16. yy'da ise hemen hemen tüm et yemeklerinde kişniş, kimyon ve tarçın kullanılmıştır. Bu üçlünün dışında yemeğin malzemesine göre, zencefil ile karanfil baharatları da Osmanlı mutfağında yer almıştır (Yerasimos, 2014: 54).

Osmanlı mutfak kültüründe yer alan yemekler; Çorbalar, Kebaplar, Yahniler ve Pilakiler, Pilavlar, Hamur İşleri ve Börekler, Tatlılar, son olarak Şerbetler ve Hoşaflar olarak kategorize edilmiştir. Bu kategorize yapılırken kaynak olarak kullanılan Osmanlı mutfağı ile ilgili yemek kitapları örnek alınmıştır. Osmanlı mutfağında yer alan yemekler antioksidan baharatlar ile ilişkilendirilerek detaylı bir şekilde incelenmiştir. 
Araştırma antioksidan baharatların Osmanlı mutfak kültürlerinde yer alan kullanım durumlarını değerlendirmek ve bu kapsamda bu mutfağın varlığı boyunca Osmanlı yemek türlerinin antioksidan baharatlarla ilişkisini incelemektir.

\section{Antioksidan Baharatların Osmanlı Saray Mutfağındaki Yeri}

Osmanlı Mutfağı ile ilgili yemek kitaplarında yer alan yemeklerde kullanılan antioksidan baharatlar tablolar halinde aşağıdaki şekilde incelenmiştir. Osmanlı Mutfağı'nda yer alan yemekler Çorbalar, Kebaplar, Yahniler ve Pilakiler, Sebze Yemekleri ve Dolmalar, Hamur İşleri ve Börekler, Tatlılar, Şerbetler ve Hoşaflar başlıkları altında incelenmiştir.

\section{1. Çorbalar}

Türk mutfağının demirbaş yemeklerinden biri olan çorbalar diğer ülkeler tarafından yanlış anlaşılmaktadır. Türk mutfağının tencere yemekleri yabancılar tarafından çorba olarak adlandırılmaktadır (Şavkay, 2000: 49). Türklerin başyemeği olan çorbalarda geçmişten günümüze doğru daha farklı baharat tüketimi mevcuttur. Örneğin tavuk çorbasına tarçın ilave edilirken, işkembeci esnafında yapılan kelle paça çorbalarına tarçın ve karanfilli baharatlar serpiştirilmiştir (Samancı, 2016: 61). Osmanlı döneminde ekşili çorbalardan çok hoşlanılırdı. Bu nedenle tüm çorbalara bolca koruk (olgunlaşmamış üzüm)suyu, erik suyu, sirke ya da limon kullanılmıştır. Erken dönemde çorbalarda baharat olarak karabiber (fülfül), safran, kişniş, kimyon, 18.yüzyılda sonra ise; çoğunlukla tarçın, bol maydanoz ve nane kullanılmıştır (Yerasimos, 2014: 64). Genel olarak çorbalarda; Kırmızı pulbiber, nane, karabiber (fülfül) tüketilirken, bunlara ilaveten Ekşili lohusa çorbası, Dügün çorbası ve Yoğurtlu çorbada; kuru reyhan, kuru maydanoz, Patates çorbasında da tarçın kullanılmıştır (Şavkay, 2000: 49).

Yapılan çalışmada Osmanlı mutfağında önemli yeri olan çorbalardan Ekşili Lohusa çorbası, Düğün çorbası, Yoğurtlu çorba, Patates çorbası, Mercimek çorbası, Pirinç çorbası, Terbiyeli Tavuk çorbası ve Balık çorbası Tablo 2' deki şekilde incelenmiştir.

Tablo 2. Osmanlı Mutfağında Çorbalarda Kullanılan Antioksidan Baharatlar

\begin{tabular}{|c|c|c|c|c|c|c|c|c|c|}
\hline Çorbalar & 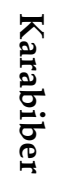 & 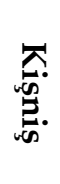 & 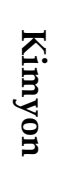 & 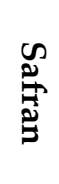 & 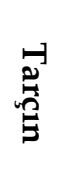 & $\begin{array}{l}N \\
0 \\
0 \\
0 \\
0 \\
2 \\
2 \\
0\end{array}$ & 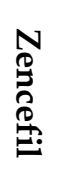 & 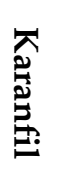 & Kaynakça \\
\hline Ekşili Lohusa Ç. & $x$ & & & & $X$ & & & & \multirow{8}{*}{$\begin{array}{c}\text { Şavkay, 2000: } 52 \\
\text { Yerasimos,2014: 65, 66, } 72 \\
\text { Efendi,2015: } 12 \\
\text { Kamil,2015: } 61 \\
\text { Akkor,2016: } 52 \\
\text { Akkor,2017: } 37\end{array}$} \\
\hline Buğday Çorbası & $X$ & & & & $X$ & & & & \\
\hline Badem Çorbası & $X$ & & & & & & & & \\
\hline Patates çorbası & & & & & $X$ & & & & \\
\hline Mercimek çorbası & $x$ & $x$ & $x$ & & & & & & \\
\hline Pirinç çorbası & $X$ & & & $x$ & & & & & \\
\hline Terbiyeli Tavuk çorba & $\mathrm{X}$ & & & $X$ & & & & & \\
\hline Balık çorbaları & & & & $X$ & $X$ & & & & \\
\hline
\end{tabular}


Mercimek çorbasında kişniş, kimyon, Ak çorbada kuru tarhun, Pirinç çorbası ve terbiyeli tavuk çorbasında safran baharatı kullanıldığı tespit edilmiştir. Şehriyeli çorba, Ekşili çorba, Terbiyeli Ciğer çorbası, Nohut çorbası ve Patates çorbasında tarçın kullanıldığı belirlenmiştir. Kaynaklarda yapılan incelemelerde de özellikle balık çorbası çeşitlerinde safran baharatının daha yaygın kullanıldığı tespit edilmiştir.

\subsection{Kebaplar}

Doğrudan ateşte veya çömlek içinde susuz pişirme yöntemini belirten Kebab sözcüğü Ortadoğu mutfak geleneğinde izgarada veya kömürde pişirilmiş et olarak algılanmaktadır. Fakat Osmanlı mutfağında kebap sözcügü daha geniş bir anlama sahiptir. Su katmadan pişirildiği sürece et, tavuk, balık, sebze hatta herhangi bir yiyecekten bile Osmanlı mutfağında kebab yapılabilmektedir (Yerasimos, 2014: 84, Şavkay, 2000: 65). Kebaplarda en çok kullanılan baharatlar tarçın ve kimyondan oluşmaktadır (Yerasimos, 2014: 85). Ayrıca koyun eti, kuyruk yağı, köfte ile hazırlanan kalyelerde kişniş, karabiber, tarçın, zencefil, safran gibi baharatlar kullanılmıştır (Samanc1, 2016: 82).

Osmanlı Mutfağı'na yer alan Kebaplar; Adi Şiş Kebabı, Gömlek Kebap, Zırbaç, Kuş Kebabı, Muhzır Kebabı, Süt Kebabı, Tavuk Külbastı, Salma Aşı şeklinde kategorize edilmiştir. Bu yemeklerin antioksidan baharatlar bakımından incelenmesi aşağıda yer alan Tablo 3 'teki gibidir.

Tablo 3. Osmanlı Mutfağında Kebaplarda Kullanılan Antioksidan Baharatlar

\begin{tabular}{|c|c|c|c|c|c|c|c|c|c|}
\hline Kebaplar & $\begin{array}{l}\text { 중 } \\
0 \\
0 \\
0 \\
0 \\
0 \\
0\end{array}$ & 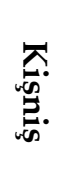 & 突 & 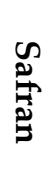 & 矛 & $\begin{array}{l}N \\
0 \\
0 \\
0 \\
0 \\
0 \\
0 \\
0 \\
0\end{array}$ & 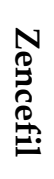 & 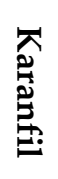 & Kaynakça \\
\hline Adi Şiş Kebabı & $X$ & & & & $X$ & & & & \multirow{8}{*}{$\begin{array}{c}\text { Şavkay, 2000: } 68 \\
\text { Yerasimos, 2014: } 107 \\
\text { Efendi,2015: 23,24 } \\
\text { Kamil,2015: 65,66 } \\
\text { Güldemir, 2016: } 102 \\
\text { Akkor,2016: } 126\end{array}$} \\
\hline Gömlek Kebap & $X$ & $X$ & & & & & & & \\
\hline Zırbaç & $X$ & $X$ & & $X$ & $x$ & & & & \\
\hline Kuş Kebabı & $X$ & & $X$ & & $X$ & & & & \\
\hline Muhzir Kebabı & $X$ & & & & $X$ & & & & \\
\hline Süt Kebabı & $X$ & & & & $X$ & & & & \\
\hline Tavuk Külbastı & $X$ & & & & $X$ & & & & \\
\hline Salma Aş1 & & & & $X$ & & $X$ & & & \\
\hline
\end{tabular}

Kebap çeşitlerinde daha öncede değinildiği gibi karabiber kullanımının daha yaygın olduğu belirlenmiştir. Kebab yemeklerinde karabiberi tarçın baharatının takip ettiği tespit edilmiştir. Gömlek kebabı olan "zırbaç" yemeğinde kişniş ve tarçın ve safran baharatının kullanıldığı tespit edilmiştir. Ayrıca Salma aşı yemeğinde safran ve zencefil baharatının kullanımı dikkat çekmiştir.

\subsection{Yahniler ve Pilakiler}

Yahniler susuz pişirilen kebapların aksine çeşitli et, sebzelerin baharat ve otlarla çeşnilendirilerek sulu bir şekilde pişirilmesidir. Yahniler genellikle, soğan, sarımsak ve 
sirke ile lezzetlendirilmiştir (Şavkay, 2000: 89). Buna ilaveten özellikle 18.yy'da balık yahnileri bol soğanlı, sirkeli, tarçınlı ve tereyağı ile pişirilmiştir. Yunanca bir sözcük olan Pilaki, zeytinyağ ile pişirilen, bol soğan ve sarımsaklı, maydanozlu ve domatesli yemek anlamına gelmektedir (Yerasimos, 2014: 169). Osmanlı dönemi mutfağında pilakilerde kullanılan baharatlara biber, tarçın, yenibahar ve bazen de mastika olarak adlandırılan sakız örnek verilebilir (Anonim, 2018).

Papaz Yahnisi, Uskumru Yahnisi, Sarımsaklı Yahni, Tavşan Yahnisi, Midye Pilakisi, Uskumru Pilakisi, İstiridye Pilakisi, Yalancı Pilaki yemekleri Osmanlı mutfak kültürü kapsamında, kullanılan antioksidan baharatlar bakımından aşağıda yer alan Tablo 4'teki şekilde incelenmiştir.

Tablo 4. Osmanlı Mutfağında Yahniler ve Pilakilerde Kullanılan Antioksidan Baharatlar

\begin{tabular}{|c|c|c|c|c|c|c|c|c|c|}
\hline Yahniler ve Pilakiler & 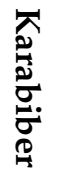 & 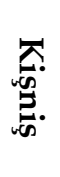 & 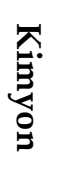 & 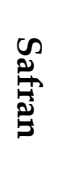 & 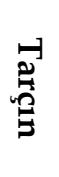 & $\begin{array}{l}N \\
0 \\
0 \\
0 \\
0 \\
0 \\
0 \\
0\end{array}$ & $\stackrel{N}{\stackrel{N}{0}}$ & 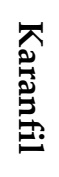 & Kaynakça \\
\hline Papaz Yahnisi & $x$ & & $x$ & & $x$ & & & & \multirow{8}{*}{$\begin{array}{c}\text { Yerasimos,2014:100 } \\
\text { Efendi,2015: 40, } 41 \\
\text { Kamil,2015: 76, } 85 \\
\text { Şavkay,2000: 102, } 104\end{array}$} \\
\hline Uskumru Yahnisi & $x$ & & & & $x$ & & & & \\
\hline Sarımsaklı Yahni & $x$ & & $X$ & & & & & & \\
\hline Tavşan Yahnisi & & $X$ & $x$ & & & & & & \\
\hline Midye Pilakisi & $x$ & & & & & & & & \\
\hline Uskumru Pilakisi & $X$ & & & & $x$ & & & & \\
\hline İstiridye Pilakisi & $X$ & & & & & & & & \\
\hline Yalanci Pilaki & & & & & $x$ & & & & \\
\hline
\end{tabular}

\subsection{Sebze Yemekleri ve Dolmalar}

Türklerin göçebe yaşamı nedeniyle, et, süt ürünleri ve bakliyatları içeren beslenme şekilleri yerleşik hayatla birlikte sebze ve meyveleri de beraberinde getirmiştir (Şavkay,2000: 163). Sebzeler gerek yahni, tava, mücver, dolmalar şeklinde gerekse sebze yemeği şeklinde tüketilmiştir. Baharatlar bakımından incelendiğinde Osmanlı mutfağında sebze yemeklerinde genel olarak karabiber (fülfül) ve tarçın yer almıştır (Yerasimos, 2014, Şavkay, 2000, Samanc1, 2016, Efendi, 2005, Kamil, 2015).

Osmanlı Mutfak Kültüründe yer alan Sebze Yemekleri ve Dolmalar; Bamya Bastısı, Güveç Bastısı, Kabak Kalyesi, Medfune, Tavuk Dolması, Halep Dolması, Kavun Dolması, Vişneli Yaprak Dolması antioksidan baharatlar bakımından aşağıda yer alan Tablo 5 'te incelenmiştir. 
Tablo 5. Osmanlı Mutfağında Sebze Yemekleri ve Dolmalar Kullanılan Antioksidan Baharatlar

\begin{tabular}{|c|c|c|c|c|c|c|c|c|c|}
\hline $\begin{array}{c}\text { Sebze Yemekleri ve } \\
\text { Dolmalar }\end{array}$ & 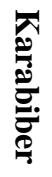 & 曹 & 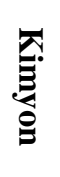 & 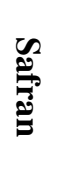 & $\begin{array}{l}\overrightarrow{0} \\
\stackrel{0}{0} \\
\hat{\theta}\end{array}$ & 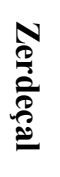 & $\begin{array}{l}\text { No } \\
\stackrel{0}{0} \\
\stackrel{3}{B}\end{array}$ & 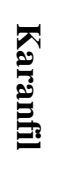 & Kaynakça \\
\hline Bamya Bastıs1 & $\mathrm{X}$ & & & & $\mathrm{X}$ & & & & \multirow{8}{*}{$\begin{array}{c}\text { Şavkay,2000: 164, 188, } 190 \\
\text { Yerasimos,2014: 194, } 202 \\
\text { Efendi, 2015: 86 } \\
\text { Kamil, 2015: 123 } \\
\text { Güldemir, 2016:105 }\end{array}$} \\
\hline Güveç Bastıs1 & $\mathrm{X}$ & & & & $\mathrm{X}$ & & & & \\
\hline Kabak Kalyesi & $\mathrm{X}$ & & & & $\mathrm{X}$ & & & & \\
\hline Medfune & & & & & $\mathrm{X}$ & & & & \\
\hline Tavuk Dolması & $\mathrm{X}$ & & & & $\mathrm{X}$ & & & & \\
\hline Halep Dolmas1 & $\mathrm{X}$ & & & $\mathrm{X}$ & $\mathrm{X}$ & & & & \\
\hline Kavun Dolmas1 & $\mathrm{X}$ & $\mathrm{X}$ & & & & & & & \\
\hline Vişneli Yaprak Dolması & $X$ & & & & $\mathrm{X}$ & & & & \\
\hline
\end{tabular}

Yapılan çalışmada sebze yemeklerinde genellikle karabiber ve tarçın baharatlarına rastlanırken, bunlara ilave olarak kavun dolmasında kişniş, Halep dolmasında safran, kullanıldığı belirlenmiştir.

\subsection{Pilavlar}

Pirinç pilavı zengin Osmanlı sofralarının başyemeği olmuştur. Ulaşılması zor ve pahalı bir ürün olduğu için 15. yy'ın başlarından itibaren "elit" bir kesimin yiyeceği olmuştur ve bulgur pilavına göre daha fazla tüketilmiştir (Yerasimos, 2014: 113). 15.yy'da Osmanlı pilavlarında safran baharatı yer alırken, 16. yy'da biberli ve meyveli pilavlar yapılmaya başlanmıştır (Akkor, 2016: 227). Yerasimos (2014: 133)'a göre 18.yy'da patlıcanlı pilav tarçınlı, safranlı ve sakızlı pişirilmiştir. Ayrıca başlı başına "ağır yemek" kategorisine giren iç pilavlarda kuru meyveler ve yemişlerin yanı sıra kakule, karanfil, yenibahar ve tarçın baharatları kullanılmıştır. Son olarak Evliya Çelebi'nin Seyahatname'sinde pilavlarda fülfül (karabiber), karanfil, safran kullanıldığı belirtilmiştir (Yerasimos, 2011: 141).

Osmanlı Mutfağı'nda yer alan pilavlar; Nohutlu Pilav, Acem Pilavı, Patlıcanlı Pilav, Özbek Pilavı, Domates Pilavı, İç Pilavı, Lüfer Pilavı, Kestaneli Bulgur Pilavı şeklinde 8 kategoride incelenmiştir. Bu yemeklerin antioksidan baharatlar bakımından değerlendirmesi aşağıdaki Tablo 6' da yer almaktadır. 
Tablo 6. Osmanlı Mutfağında Pilavlarda Kullanılan Antioksidan Baharatlar

\begin{tabular}{|c|c|c|c|c|c|c|c|c|c|}
\hline Pilavlar & 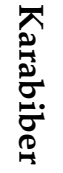 & 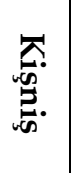 & $\begin{array}{l}\text { 절 } \\
\text { 입 }\end{array}$ & $\begin{array}{l}\mathscr{\infty} \\
\stackrel{\mathscr{D}}{\mathscr{B}}\end{array}$ & $\begin{array}{l}\overrightarrow{0} \\
\stackrel{0}{0} \\
\stackrel{\Xi}{\Xi}\end{array}$ & 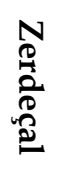 & $\begin{array}{l}\text { N } \\
\stackrel{0}{0} \\
\stackrel{0}{\Xi} \\
\stackrel{\Xi}{\Xi}\end{array}$ & 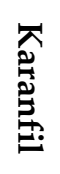 & Kaynakça \\
\hline Nohutlu Pilav & & & & $x$ & & $X^{*}$ & & & \multirow{8}{*}{$\begin{array}{l}\text { Şavkay, 2000: 210, } 112 \\
\text { Yerasimos, 2014: 120,137 } \\
\text { Efendi, 2015: 110 } \\
\text { Kamil, 2015: 130 } \\
\text { Güldemir, 2016: } 108 \\
\text { Akkor, 2017: } 115\end{array}$} \\
\hline Acem Pilavı & $x$ & & & & $x$ & & & $x$ & \\
\hline Patlicanlı Pilav & $x$ & & & $x$ & & & & & \\
\hline Özbek Pilavı & & & & & $X$ & & & $x$ & \\
\hline Domates Pilav1 & $\mathrm{X}$ & & & & & & & & \\
\hline İç Pilavi & $x$ & & & & $X$ & & & & \\
\hline Lüfer Pilavı & & & & & $X$ & & & & \\
\hline Kestaneli Bulgur Pilavı & & & $x$ & & & & & & \\
\hline
\end{tabular}

* Safranın yerine ikame olarak zerdeçal baharatının kullanıldığı tespit edilmiştir.

Çalışmaya göre; pilavlarda çoğunlukla kullanılan baharatın karabiber ve tarçın olduğu belirlenmiştir. Her iki baharatın da birlikte bulunduğu yemekler, Acem pilavı ile İç pilavı olarak tespit edilmiştir. Safran baharatı Nohutlu Pilav ve Patlıcanlı Pilavda kullanılırken, Karanfil baharatının Acem Pilavı ve Özbek Pilav'ında kullanıldığı belirlenmiştir. Ayrıca nohutlu pilavda zerdeçal, Kestaneli bulgur pilavında ise kimyon baharatı kullanıldığı tespit edilmiştir. Yapılan çalışmada safranın yerine ikame olarak zerdeçal baharatının kullanıldığı belirlenmiştir.

\subsection{Hamur İşleri ve Börekler}

Piruhi, Mant1, Tatar Böreği, Pırasa Böreği, Soğan Böreği, Tas (Kapak Böreği) Böreği, Reştiyye, Salma Aşı, Vetrika, Peynir Lokması, Kalacoş, Türk Böreği (Alt-Üst börek), Nemse (Gelincik) Böreği, Su böreği, Tavuk Böreği, Paça Böreği, Fincan Böreği, Puf Böreği, Peynirli Pide, Mihtap (Kol) Böreği, Akıtma Böreği, Laganda, Peynirli Katmer gibi hamur işleri ürünleri antioksidan baharatlar açısından incelenmiştir. Bu yemek ürünlerinden mantı yemeğinde ve kıymalı iç harçlarında genellikle baharat olarak karabiber kullanıldığı tespit edilmiştir. Bunlardan farklı olarak Soğan böreği ve Tas (Kapak) böreğinde baharat olarak karabiberin yanı sıra tarçının da kullanıldığı belirlenmiştir (Akkor, 2016, Efendi, 2005, Şavkay, 2000, Kamil, 2015, Yerasimos, 2014).

\subsection{Tatlılar}

Osmanlı mutfak kültüründe yer alan Zerde, Mesir Macunu, Helva-i Hakani, Badem Kurabiyesi, Ayva ve Armut Tatlısı, Patlıcan Tatlısı, Tavuk Göğsü, Cevizli Tel Kadayıf tatlıları kullanılan antioksidan baharatlar bakımından aşağıda yer alan Tablo 7'da incelenmiştir. 
Tablo 7. Osmanlı Mutfağında Tatlılarda Kullanılan Antioksidan Baharatlar

\begin{tabular}{|c|c|c|c|c|c|c|c|c|c|}
\hline Tatlılar & 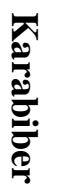 & 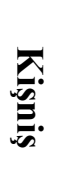 & 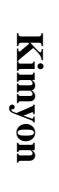 & 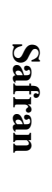 & $\begin{array}{l}\overrightarrow{0} \\
\stackrel{0}{\Xi}\end{array}$ & 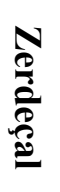 & 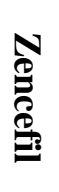 & 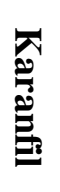 & Kaynakça \\
\hline Zerde & & & & $X$ & & $x$ & & & \multirow{8}{*}{$\begin{array}{c}\text { Savkay, 2000: 238,248 } \\
\text { Yerasimos, 2014: 271, 281, } 284 \\
\text { Efendi, 2015: 136,184, } \\
\text { Kamil, 2015:136 }\end{array}$} \\
\hline Mesir Macunu & & $X$ & & & $x$ & & $\mathrm{X}$ & $\mathrm{X}$ & \\
\hline Helva-i Hakani & & & & & $x$ & & & & \\
\hline Badem Kurabiyesi & & & & & $x$ & & & $x$ & \\
\hline Ayva ve Armut Tatlisı & & & & & $x$ & & & $X$ & \\
\hline Patlıcan Tatlısı & & & & & $x$ & & & & \\
\hline Tavuk Göğsü & & & & & $x$ & & & & \\
\hline Cevizli Tel Kadayıf & & & & & $x$ & & & & \\
\hline
\end{tabular}

Yapılan bu incelemede tatlı türlerinde en çok kullanılan antioksidan baharatın tarçın olduğu tespit edilmiştir. Tarçından sonra mesir macunu, badem kurabiyesi ile ayva ve armut Tatlısında kullanılan karanfil olduğu belirlenmiştir. Ayrıca zerde tatlısında safran ve zerdeçal kullanılırken, mesir macununda kişniş ve zencefil kullanıldığı tespit edilmiştir.

\section{8. Şerbetler, Hoşaflar}

Yapılan incelemede şerbet ve hoşaflarda baharat kullanımının yaygın olmadığı tespit edilmiştir. Yalnızca Vişne şerbetinde karanfil baharatının kullanıldığı belirlenmiştir (Şavkay, 2000, Yerasimos, 2014, Efendi, 2015, Kamil, 2015, Akkor, 2017).

\section{Sonuç ve Değerlendirme}

Temelde dinsel (örneğin tütsüde) ritüellerde kullanılan baharat aynı zamanda geçmişte ve günümüzde insanların tat alma zevkine hitap etmiş ve sağlıklı yaşam amacıyla da kullanılmıştır. Ortaçağ ve ortaçağ sonrası Avrupa'dan farklı olarak, Osmanlı mutfağında baharatlar aşırı tüketilmemiş dahası ılımlı bir şekilde kullanmıştır. Osmanlı aşçıları yiyeceklerin doğal lezzetini arttırmak için ürünlerini hafifçe baharatlamışlardır. Çalışmada da belirtildiği gibi Osmanlı Saray yemekleri antik Roma, Avrupa ya da Arap mutfağının tersine, ne karışık baharatlı ne de çok salçalı olmuştur. Hatta 18. yy'dan sonra yemekler, baharat karışımları açısından da iyice sadeleşmiştir.

Antioksidan baharatlar insanlığın var olduğu dönem boyunca kullanılmaya devam etmiştir. Osmanlı saray mutfağında kullanılan antioksidan baharatlar, yemeklerde hem lezzetlendirici hem de renklendirici amacıyla kullanılmıştır. Antioksidan baharatların Osmanlı Saray mutfağındaki yerini vurgulamayı amaçlayan bu çalışmada şu sonuçlara ulaşılmıştır;

- Araştırmada Osmanlı yemeklerinde kullanılan baharatlara bakıldığında en çok karabiber ve Tarçın baharatlarının kullanıldığı tespit edilmiştir. Karabiber tuzlu yemeklerde kullanılırken, tarçın hem tuzlu hem de tatlı yemeklerde kullanıldığı belirlenmiştir. Özellikle et yemekleri, pilavlar ve dolmalarda en çok karabiber 
ve tarçın baharatları görülmüştür. Tez (2015: 140)'e göre; başta karabiber(kara altın) ve tarçın egemen sınıfın statü simgesi ve güç göstergesi olmuştur. Hükümdarların birbirine 'karabiber' armağan ettiği, kimi zaman ödemelerin altın yerine karabiber baharatıyla yapıldığı belirtilmiştir. Karabiber ve tarçın baharatının bu kadar önemli olması yemeklerdeki kullanım sıklığı ile ilişkilendirilebilir.

- Zerdeçal baharatının kebap ve pilav yemeklerinde ve tatlılarda kullanıldığı, zencefil baharatının ise yalnızca tatlılarda yer aldığım tespit edilmiştir.

- Yapılan çalışmada safran baharatının yerine ikame olarak zerdeçal baharatının da kullanıldığı saptanmıştır. Bu durum zerdeçal ve safran baharatlarının lezzet olarak birbirine benzer olduğundan değil, yemeklere aynı renkleri verdiği için kullanıldığı düşünülmektedir.

- Karabiber baharatının muhakkak görüldüğü çorbalarda safran ve tarçının da önemli olduğu belirlenmiştir. Kaynaklarda yapılan incelemelerde balık çorbası çeşitlerinde özellikle safran baharatının kullanıldığ 1 tespit edilmiştir. Yerasimos (2014: 54)'a göre safran baharatı pilavlarda, yahnilerde hatta tatlılarda hem lezzetlendirici hem de renklendirici olarak kullanılmıştır. Fakat burada safran baharatının özellikle balık ürünlerinde görülme nedeninin balıktaki ağır kokuyu giderme ve tatlandırma amaçlı olabileceği düşünülmüştür.

- Kebaplarda önemli rol üstlenen baharatlar karabiber ve tarçın olmuştur. Kişniş, safran, kimyon ve zerdeçal gibi antioksidan baharatların da kebaplar da yer aldığı belirlenmiştir.

- Osmanlı mutfağında pilavlarda kullanılan baharatlar, karabiber, tarçın ve safran olarak belirlenmiştir. Bunların dışında, Acem pilavı ve Özbek pilavında karanfil, kestaneli bulgur pilavında da kimyon baharatının kullanıldığı tespit edilmiştir.

- Tatlılarda en çok kullanılan antioksidan baharatların tarçın ve karanfil olduğu belirlenmiştir. Diğer antioksidan baharatlardan kişniş, zerdeçal, zencefil ve safranın da tatlılarda kullanıldığı saptanmıştır. Tarçın, karanfil, zencefil ve zerdeçal gibi sıcak baharatların aromatik yoğunluğunun tatlılara daha çok yakıştığı düşünülmüş olabilir. Aynı zamanda bu sıcak baharatların ilaç olma vasıfları ön planda olduğundan (Gürsoy, 2012; 32) tedavi amaçlı tatlılara katıldığ1 da düşünülebilir.

- Son olarak Osmanlı yemekleri ile ilgili incelenen kaynaklarda yemeklerde kullanılan baharatların tanımlanmasında 'antioksidan' terimine rastlanmamıştır. Baharatların daha çok lezzetlendirme, var olan lezzeti güçlendirme, renklendirme ve tedavi amaçlı (ilaç) olarak kullanıldığı tespit edilmiştir. 


\section{Kaynakça}

Akkor, Y.E. (2016). Gelenekten Evrensele Osmanlı Mutfağı. İstanbul: Alfa Yayınları.

Akkor, Ö. (2017). Ömür Akkor ile Osmanlı'dan Günümüze Türk Mutfağı. İstanbul: Olimpos Yayınları.

Anonim, (2018). Yahniler ve Pilakiler Hakkında Bilgi, http://osmanlisofrasi.blogspot. Com/2010/12/yahniler-ve-pilakiler-hakkinda-bilgi.html(10.02.2019).

Aschl, M. (2010). Baharat ve Otlarla Şifalı Yemek Tarifleri. İstanbul: Kaknüs Yayınları.

Aydın, H. (2011). Bazı Baharatların Farklı Ekstraktlarmın Antioksidan Özelliklerinin Belirlenmesi(Yüksek Lisans Tezi). Edirne: Trakya Üniversitesi Fen Bilimler Enstitüsü.

Beyzi, E. ve Güneş, A. (2017). Kişniş (Coriandrum sativum L.) Bitkisinin Uçucu Yağ Bileşenleri Üzerine Bor Uygulamasının Etkileri, Gaziosmanpaşa Üniversitesi Ziraat Fakültesi Dergisi, 34 (1): $146-152$.

Bilgin, A. (2004). Osmanlı Mutfă̆̆(1453-1650). İstanbul: İstanbul Kitapevi Yayınları.

Bulduk, S. (2013). Gıda Teknolojisi, Ankara: Detay Yayınları

Coşkun, R., Altuışık, R. ve Yıldıım, E. (2017). Sosyal Bilimlerde Araştırma Yöntemleri. Sakarya: Sakarya Yayıncilık.

Çoban, Ö.E. ve Patır, B. (2010). Antioksidan Etkili Bazı Bitki ve Baharatların Gıdalarda Kullanımı, Gida Teknolojileri Elektronik Dergisi, 5(2): 7-19.

Çolak, H. ve Ulusoy, B.H. (2005). Bitkisel Orijinli Gıdalarda Bulunan Bazı Antioksidan Maddeler ve Etkileri, Gida ve Yem Bilimi Teknolojisi, 8: 43-48.

Demirçivi, B.M. ve Altaş, A. (2016). Üniversite Öğrencilerinin Baharatlara İlişkin Bilgileri ve Tüketim Tercihleri: Aksaray Üniversitesinde Bir Uygulama, Journal of Tourism and Gastronomy Studies, (4)4: 88-112.

Efendi, T. (2005). Osmanlı Mutfağı, İstanbul: Dönence Yayın Yayınları.

Faydaoğlu E. ve Sürücüoğlu M.S. (2011). Geçmişten Günümüze Tıbbi ve Aromatik Bitkilerin Kullanılması ve Ekonomik Önemi, Kastamonu Üniveristesi, Orman Fakültesi Dergisi, 11 (1): $52-67$.

Güldemir, O. (2016). Yemekler: Uygulama Örnekleri, Osmanlı Mutfă̆ı(Ed: Bilgin, A. ve Önçel, S.). Eskişehir: Anadolu Üniversitesi Yayınları.

Göncü, B. ve Akın, M.S. (2017). Baharat Çeşitlerinin Peynirde Kullanımı, Harran Üniversitesi Mühendislik Dergisi, 1: 44-53.

Gürsoy, D. (2012). Baharat ve Güç, İstanbul: Oğlak Yayınları

Gürsoy, D. (2013). Tarihin Süzgecinde Mutfak Kültürümüz. İstanbul: Oğlak yayınları.

Gürson, O. ve Özçelikay, G. (2005). Tarçın'ın Tarih Boyunca ve Günümüzdeki Kullanımı, dergipark.ulakbim.gov.tr/otam/article/view/5000085247(5.05.2018).

İnoltong, T. (2016). Bir Ot Masall. İstanbul: İletişim yayınları

Kamil, M. (2015). Melceü't- Tabbâhin Aş̧̧ıların sığınağı. İstanbul: Türkiye Yazma Eserler Kurumu Başkanlığı. 
Kar, Y., Şen, N. ve Tekeli,Y. (2007). Samsun Yöresinde ve Mısır Ülkesinde Yetiştirilen Çörekotu (Nigella sativa L.) Tohumlarının Antioksidan Aktivite Yönünden İncelenmesi, Süleyman Demirel Üniversitesi, Fen Edebiyat Fakültesi, Fen Dergisi, 2(2): 197-203.

Keykubat, B. (2016). Tıbbi Aromatik Bitkiler ve İyi Yaşam. İzmir: Ticaret Borsası Ar-Ge Müdürlüğü.

Kızıldemir, Ö., Öztürk E. ve Sarışık, M.(2014). Türk Mutfak Kültürü'nün Tarihsel Gelişiminde Yaşanan Değişimler, Abant İzzet Baysal Üniversitesi, Sosyal Bilimler Enstitüsü Dergisi, 14(3): 191-210.

Koca, N. ve Karadeniz, F.(2005). Gıdalardaki Doğal Antioksidan Bileşikler, Gıda Dergisi, 30(4): 229-236.

Lewicka, P.B. (2011). Flavorings in Context: Spices and Herbs in Medieval Near East, Rocznnik Orientalistyczny, T. LXIV, Z., 1: 140-149.

Lobo, V., Patil, A., Phatak, A. and Chandra N. (2010). Free radicals, antioxidants and functional foods: Impact on human health, Pharmacogn Rev., 4(8): 118-126.

Mete, O. (2017). Baharatlar Soframızın Lezzeti, Ağzımızın Tadı. İstanbul: Alfa Basım Yayım.

Narsimhan, S. (2009). Plants and Human Civilization: Indian Spices, Comparative Civilizations Review, 60(8): 120-149.

Paur, I., Carlsen, M.H., Halvorsen, B.L.ve Blomhoff, R. (2011). Antioxidants in Herbs and Spices: Roles in Oxidative Stress and Redox Signaling. Herbal Medicine: Biomolecular and Clinical Aspects, (Ed: Benzie, I. F. F. and Wachtel-Galor). CRC Press/Taylor \& Francis.

Samancı, Ö. (2016). Halk Mutfağı, Osmanlı Mutfağı. (Ed: Bilgin, A. ve Önçel, S.). Eskişehir: Anadolu Üniversitesi Yayınları.

Stanwey, P. (2013). Baharatlar, Mucize Gıdalar(Serpil Demirci Çev.). İstanbul: Kuraldışı Yayıncilik.

Şavkay, T. (2000). Osmanlı Mutfă̆̆, İstanbul: Şekerbank.

Uğur, Ş. ve Kan, Y. (2016). Ankara (Gölbaşı) Şartlarında Farklı Ekim Zamanlarında Yetiştirilen Kimyon(Cuminum cyminum L.)'un Verim ve Kalite Özelliklerinin Belirlenmesi, Selçuk Tarım Bilimleri Dergisi, 3(2): 205-209.

Tez, Z. (2015). Lezzetin Tarihi Geçmişten bugüne yiyecek, İçecek ve Keyif Vericiler, İstanbul: Hayy Kitap.

Tunçtürk, R. (2011). Kişniş (Coriandrum sativum L.) Çeşitlerinde Değişik Ekim Mesafelerinin Verim ve Kalite Üzerine Etkisi, Yüzüncü Yal Üniversitesi Tarım Bilimleri Dergisi, 21(2): 8997.

Türkan, C. (2010). Mutfak Teknolojisi, Bolu: Sistem Ofset.

Öğüt, S.(2014). Doğal Antioksidanların Önemi, Adnan Menderes Üniversitesi Ziraat Fakültesi Dergisi, 11(1): 25 - 30.

Yalçın, A. (2000). Baharat Dünyası, Baharat ve Popüler Otlar Ansiklopedisi. İstanbul: Geçit Kitabevi.

Yerasimos, M.(2011). Evliya Çelebi Seyahatnamesi'nde Yemek Kültürü, Yorumlar ve Sistematik Dizin, İstanbul: Kitap Yayınevi.

Yerasimos, M. (2014). 500 Yıllık Osmanlı Mutfağı. İstanbul: Boyut Yayıncılık. 
Yeşilada, E. (2012). İyileştiren Bitkiler, İstanbul: Hayykitap.

Yıldırım, A. ve Şimşek, H. (2013). Sosyal Bilimlerde Araştırma Yöntemleri. Ankara: Seçkin Yayıncilik.

Yiğit, A. (2016). Baharatlar. Gıda Coğrafyası, (Ed: Aktaş, S.G.). Anadolu Üniversitesi Yayınları. Eskişehir. 